\title{
Effect of Nasal Surgery in Patients with Remained Snoring and Sleep Apnea after Obstructive Sleep Apnea Surgery
}

\author{
Dae Woong Kim, Nam Kook Kim, Wee Hwang Kim, Jang Su Lee, and Dong Jin Choi \\ Department of Otolaryngology-Head and Neck Surgery, Kwangju Christian Hospital, Gwangju, Korea
}

\author{
폐쇄성 수면무호흡증후군 수술 후 잔존 증상이 남아 있는 환자에서 코 수술이 증상 호전에 미치는 영향 \\ 김대웅 · 김남국 · 김위황 · 이장수 · 최동진 \\ 광주기독병원 이비인후과
}

\author{
Received March 14, 2016 \\ Revised June 8, 2016 \\ Accepted June 11, 2016 \\ Address for correspondence \\ Dong Jin Choi, MD \\ Department of Otolaryngology- \\ Head and Neck Surgery, \\ Kwangju Christian Hospital, \\ 37 Yangnim-ro, Nam-gu, \\ Gwangju 61661, Korea \\ Tel $+82-62-650-5095$ \\ Fax $+82-62-650-5090$ \\ E-mailsdadazur@naver.com
}

Background and Objectives Obstructive sleep apnea syndrome is one type of sleep disorder breathing. During sleep, in respiration, nasal obstruction causes negative pressure, which in turn causes the pharyngeal airway to collapse during inspiration. We investigated how nasal surgery affects patients who have undergone OSA surgery but still suffer from the remaining symptoms of snoring and sleep disorder breathing.

Subjects and Method We reviewed 24 patients, who had undergone obstructive sleep apnea (OSA) surgery only to show no enhancement in snoring and qualities of sleep; they showed nasal septal deviation or inferior turbinate hypertrophy. Septal surgery or inferior turbinoplasty was performed by the same otolaryngologist. Over the period between preoperation and 1, 3, 6, 12 months after operation, we evaluated Apnea-Hypopnea Index (AHI) and oxygen saturation by polysomnography, degree of snoring by Visual Analogue Sacle (VAS) score, satisfaction for quality of sleep by Epworth Sleepiness Scale (ESS), minimal cross section area and volume of nasal cavity by acoustic rhinometry, respectively.

Results After nasal surgery, the volume of nasal cavity and MCA increased. There were significant improvements of AHI, oxygen saturation, VAS and ESS score.

Conclusion As for OSA surgery, the evaluation of nasal cavity is an indispensible factor for improving the quality of sleep and snoring. When treating OSA patients who have nasal obstruction, nasal surgery including septoplasty and inferior turbinoplasty should be considered. Korean J Otorhinolaryngol-Head Neck Surg 2016;59(8):588-92

Key Words Nasal obstruction · Nasal surgery $\cdot$ Obstructive sleep apnea syndrome $\cdot$ Snoring.

\section{서 론}

폐쇄성 수면무호흡증(obstructive sleep apnea syndrome) 이란 수면 호흡장애(sleep disordered breathing) 중의 하나 로 수면 중 상기도가 완전히 혹은 부분적으로 막히게 되어 무호흡이나 저호흡과 같은 환기장애를 발생시키는 것을 말 한다. 이로 인하여 주기적인 혈중 산소포화도의 변화가 생겨 수면분절로 인하여 수면의 질을 악화시키고, 주간 졸림, 인지
기능 장애 등을 악화시켜 삶의 질을 떨어뜨려 결국 고혈압, 심근경색 등 심혈관계 부작용도 나타나게 되고 심한 경우 사 망에도 이르는 질환이다. ${ }^{1)}$ 이에 대한 치료는 위험인자의 제 거, 약물치료 등의 비수술적 치료와 지속적인 기도 양압술, 구강 내 장치 등의 기구 요법, 그리고 비강 수술, 인두부 수술 등 수술적 치료가 있고, 수술적 치료로는 구개수구개인두성 형술, 레이저 구개수구개성형술, 구개수구개피판술, 고주파 구개 축소술, 정중 설 절제술, 고주파 설근부 축소술, 이설근 
전진술, 설골근 절개 거상술, 상하악 전진술, 기관절개술 등 이 있다.,6) 이중 구개수구인두성형술은 수면무호흡증후군 환 자의 치료에 있어서 대표적인 수술 방법 중 하나이지만 전체 적인 성공률은 $40 \%$ 정도로 보고되고 있으며, 특히 중증의 수면무호흡 환자의 경우 그 성공률이 낮다.2)

저자들은 최근 수면무호흡증후군의 수술을 받은 환자들 중 주관적 증상의 개선이 적다고 호소한 몇몇 환자들을 관찰 한 결과 공통적으로 비중격 만곡증 또는 하비갑개비대증이 있다는 것을 발견하였으며, 이들에게서 코 수술 시행 후 주관 적 증상과 수면다원화검사의 무호흡-저호흡 지수(ApneaHypopnea Index, AHI) 및 산소포화도의 호전을 가져온 증 례들을 분석하여 수면무호흡증후군 수술 후 추가적인 코 수 술의 효용성을 알아보고자 하였다.

\section{대상 및 방법}

\section{대 상}

2011년 1월부터 2014년 12월까지의 기간에 본원 이비인후 과에 내원한 환자들 중 본원과 타 병원에서 수면무호흡증후 군 수술을 받았으나, 코골이나 수면무호흡증후군 증상이 개 선되지 않았다고 호소하는 환자 45 명을 대상으로 하였다. 만 성 부비동염, 비용종을 가진 환자, 소악증(micrognathia)인 환자, 고혈압, 당뇨 등 기저질환이 있는 환자는 대상에서 제외 하였다. 45 명의 환자 중 비내시경 및 부비동 전산화단층촬영 과, $4 \%$ 리도카인과 1:100000 에피네프린을 섞은 용액을 면 거즈에 묻혀 15 분간 비강에 패킹을 이용해 비점막 수축을 확 인하여 진단된 양측 하비갑개 비대증 및 비중격 만곡증 또 는 둘 모두 관찰되는 29 명을 최종 대상자로 선정하였다.

환자들의 성비는 남자는 16 명, 여자가 13 명으로 평균 연령 은 45.7세였으며, 수면무호흡증후군 수술 후 본원에 내원하기 까지 평균 기간은 14.4 개월이었다. 이전에 구개수구개인두성 형술을 받은 환자가 16 명, 레이저 구개성형술을 받은 환자가 7 명, 구개근절제술(palatal muscle resection)을 받은 환자가 4 명이었으며 나머지 2명은 본인이 받은 술식에 대해 알지 못 하였다.

\section{수술 방법}

모든 수술은 동일 의사에 의해 집도되었으며, 환자는 전신 마취하에 수술을 시행하였고 비중격 교정술을 받은 환자는 9명, 하비갑개 절제술 및 Coblator ${ }^{\circledR}(\mathrm{EVac} 70$; Arthrocare corporation, Sunnyvale, CA, USA)를 이용한 하비갑개 성형 술을 받은 환자는 12 명, 동시에 수술받은 환자는 8 명이었다. 구강과 인두부에 대한 수술은 하지 않았다.
술 후 추적 관찰 기간은 최소 5 개월에서 14 개월까지 평균 12.4개월이었다.

\section{음향 비강통기도 검사}

하비갑개 수술 및 비중격 교정술 이후의 객관적인 호전 정 도를 비교하기 위해 모든 환자에게 수술 전과 수술 후 1 개월, 3 개월, 6 개월, 12 개월에 음향 비강 통기도 검사를 시행하였 다. 비점막 충혈 수축제를 사용하기 전에 비강 내 분비물 제거 한 후 약 20 분 후에 측정된 값을 비교대상으로 하였고, 각 비강 에 대해 최소 단면적(minimal cross section area, $\mathrm{MCA}$ )과 비 공으로부터 후방 $7 \mathrm{~cm}$ 까지의 비강용적(V7)을 측정하였다.

\section{수면다원화검사}

수면다원화검사는 Embla ${ }^{\circledR}$ N7000(Natus Medical Inc., San Carlos, CA, USA)을 이용하여 오후 11시부터 익일 오전 7시까지 시행되었다. 본 연구에서는 무호흡-저호흡지수를 이용 하여 수술 후의 증상의 경감을 진단하였다. 저호흡(hyponea) 은 10초 이상 일호흡량(tidal volume)이 $30 \%$ 이상 감소와 산 소포화도가 $4 \%$ 이상 저하된 상태를, 무호흡(apnea)은 Ther$\mathrm{mal}$ sensor를 이용하여 구강과 비강을 통한 호흡기류가 10초 이상 정지된 상태로 정의하였다. 무호흡-저호흡지수는 저호 흡과 무호흡 횟수를 총 수면시간으로 산출하였다.

환자들은 비중격 교정술 및 하비갑개 수술받기 전 1차 수 면다원화검사를 시행하였고, 수술 후 3 개월째에 2차 수면다 원검사를 시행하여 수술 전과 수술 후의 무호흡-저호흡지수 와 평균 산소포화도를 비교하였다.

\section{코골이의 정도 및 환자의 만족도}

수술 후에 코골이의 정도를 보기 위해 모든 환자에게 술 전과 술 후 1개월, 3개월, 6개월, 12개월에 Visual Analogue Sacle(VAS)를 이용하여 설문조사를 시행하였다. 코골이 정도 는 0점은 코골이가 전혀 없는 상태, 10 점은 코골이가 가장 심 한 상태라고 설명하여 환자가 주관적인 코골이 정도를 점수 로 내도록 하였다. 수술 후 상태에 만족하는지에 대해서는 Epworth Sleepiness Scale(ESS)을 이용하여 설문조사하여 점 수를 내었다.

\section{통계학적 분석}

모든 통계분석은 SPSS 17.0(SPSS Inc., Chicago, IL, USA) 을 이용하였고 수술 전후의 코골이 및 환자의 만족도, 그리고 음향비강 통기도 검사는 Wilcoxon signed rank test로, 수면 다원화검사는 paired t-test로 분석하였으며, $p$ 값이 0.05 미 만인 경우를 통계학적으로 유의한 것으로 판단하였다. 


\section{결 과}

수술 후 3개월까지 탈락한 환자가 없었으나, 6개월째에 2명, 12 개월째에 3 명의 환자가 개인 사정의 이유로 탈락하였고, 최 종 통계분석에 포함된 환자는 24명이었다.

\section{음향 비강통기도 검사}

수술 전 $\mathrm{MCA}$ 는 수술 전 평균 $0.17 \pm 0.09 \mathrm{~cm}^{2}$ 였고, 수술 후 1 개월째, 3 개월째, 6 개월째, 12 개월째 각각 평균 $0.51 \pm$ $0.14,0.62 \pm 0.12,0.65 \pm 0.11,0.63 \pm 0.21 \mathrm{~cm}^{2}$ 로 통계학적으로 유의하게 증가된 결과를 보였다. 또한 V7은 수술 전 평균 $4.79 \pm 0.14 \mathrm{~cm}^{3}$ 였고, 수술 후 1개월, 3 개월, 6 개월, 12 개월째 결과는 각각 평균 $5.42 \pm 1.04,6.14 \pm 1.43,6.42 \pm 1.37,6.34 \pm$ $1.49 \mathrm{~cm}^{3}$ 로 통계학적으로 유의하게 증가된 결과를 보였다 (Fig. 1).

\section{수면다원화검사}

수술 전 평균 $\mathrm{AHI}$ 값이 $28.3 \pm 0.9$ 였으나, 수술 후 3 개월째 시행한 수면다원화검사상, 평균 $\mathrm{AHI}$ 값이 $11.7 \pm 1.1$ 이었다. 이 는 통계학적으로 유의하였다. 또한 평균 산소포화도는 수술 전 83 94\%로 평균 87.5 $\pm 1.2 \%$ 였으나, 수술 후 86 96\%로 평 균 $91.4 \pm 0.8 \%$ 로 통계학적으로 유의하게 증가하였다(Fig. 2).

\section{코골이 및 $\mathrm{ESS}$ 의 정도 변화}

코골이는 수술 전 VAS 7.91 1.12 점으로 코골이가 심하였으 나, 수술 후 1개월, 3 개월, 6 개월, 12 개월째 각각 $6.12 \pm 0.78$, $5.73 \pm 0.97,4.97 \pm 1.31,4.24 \pm 0.84$ 점으로 감소하였고 이는 통

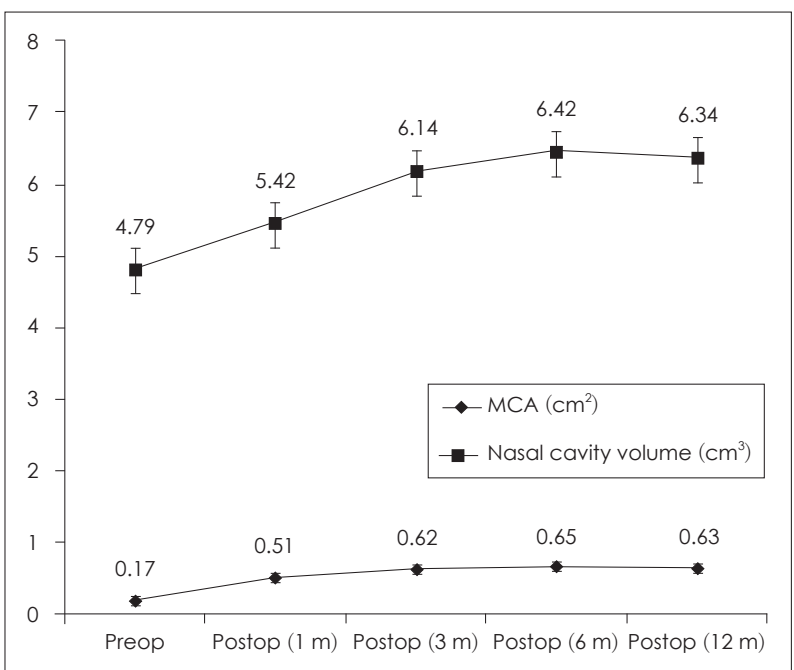

Fig. 1. Graph shows the change of nasal patency in acoustic rhinometry measured at preoperation and 1, 3, 6, 12 months after nasal surgery. MCA: minimal cross section area, preop: preoperation, postop: postoperation, m: month.
계학적으로 유의하였다. ESS는 수술 전 $12.41 \pm 0.81$ 점이었으 나, 수술 후 1 개월, 3 개월, 6 개월, 12 개월째 각각 $6.43 \pm 0.91$, $5.74 \pm 1.12,4.87 \pm 1.51,4.15 \pm 1.34$ 점으로 통계학적으로 유의 한 개선 효과를 보였다(Fig. 3).

\section{고 찰}

수면 호흡장애에는 코골이부터 시작하여 상기도 저항 증후 군, 심할 경우 폐쇄성 수면무호흡증을 포함한다. 이러한 수면 호흡장애는 공통적으로 좁아진 기도에 의한 증상을 호소한 다. ${ }^{34)}$ 그래서 여러 수술 방법을 통해 이러한 증상으로부터 개 선을 하고자 많은 연구가 이뤄져 왔다. 그러나 상기도 폐쇄는 구강, 인두, 후두뿐만 아니라 비강, 비인두 부위 폐쇄도 포함 되기 때문에 수술의 계획에 있어서 정확한 폐쇄부위의 확인 과 진단 그리고 적절한 수술 방법의 선택이 중요하다고 할 수 있겠다. ${ }^{78)}$ 그러나 수술적 치료로 많이 쓰이고 있는 구개수구 개인두 성형술은 성공률이 40\%밖에 되지 않아 수술받은 많

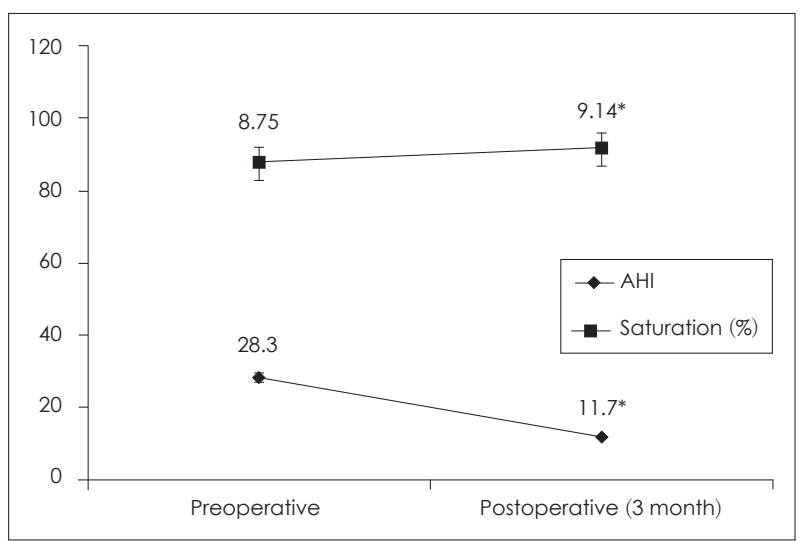

Fig. 2. Comparison of preoperative and postoperative PGS findings. ${ }^{*} p<0.05$ by paired t-test. PSG: polysomnography, AHI: ApneaHypopnea index.

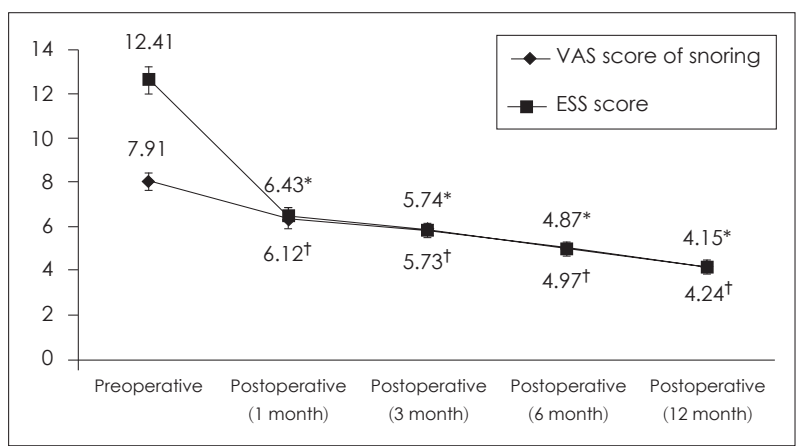

Fig. 3. Graph shows the change regarding VAS score of snoring and ESS score of patient's satisfaction of sleep after nasal surgery. Above scores were checked at preoperative and postoperative 1 , $3,6,12$ months. ${ }^{*} p<0.05$ ESS score by Wilcoxon signed rank test, ${ }^{\dagger} p<0.05$ VAS score by Wilcoxon signed rank test. VAS: Visual Analogue Scale, ESS: Epworth Sleepiness Scale. 
은 환자들이 코골이, 수면 저호흡 및 무호흡이 다시 생겨 수 면의 질이 떨어지는 것을 보게 되고 그러한 환자들을 대상으 로 신체검진을 하게 되면 많은 수에서 비중격만곡증 및 하비 갑개 비대증 같은 비폐색 및 비강기도저항이 있음을 알게 된 다." Ellis 등이은 비강기도저항 및 비폐색은 전체 기도저항 의 약 절반을 차지하는 중요한 기능적 구조이고 이는 코골이 및 폐쇄성 수면무호흡증 발생에 있어서 중요한 역할을 한다 는 것이 알려져 있을 뿐 아니라 이러한 증상을 동반한 환자에 서 비중격 교정술이 증상호전에 효과가 있다고 보고하였다. Olsen 등1ㅣ은 같은 환자가 같은 자세로 수면 시에는 각성 시 보다 구강기도저항이 비강기도저항에 비해 커진다고 보고하 였다. 즉, 수면 시에 구강의 연부 조직 또는 근육의 긴장이 떨 어져 저항이 커지게 되고 이러한 점 때문에 정상인의 경우 수 면시 코로 숨을 쉬게 된다. 그러나 비중격 만곡증 또는 하비 갑개 비대증이 있을 때는 정상적인 비강호흡이 어려워져 구 강호흡을 의존하게 되고 좁아진 구강과 인두를 통과하는 공 기가 음압을 일으켜 진동 및 폐쇄가 일어날 수 있다.

Elsherif와 Hussein ${ }^{12)}$ 에 따르면 비폐쇄 증상과 코골이 동 반한 환자들에게서 코 수술(비중격교정술, 비성형술, 비용종 제거술)을 시행하였고 $50 \%$ 환자에서 완전히 코골이가 호전 되었고, $40 \%$ 환자에서 부분적으로 호전되었다고 보고하였 다. 또한 Sufioğlu 등 ${ }^{13)}$ 에 의하면 폐쇄성 수면무호흡증에서 단독 코 수술은 AHI 및 산소포화도는 괄목할만한 호전을 보이지는 않았지만, 코골이 및 수면의 질 등 주관적 증상이 호전을 보인다고 하였고, 폐쇄성 수면무호흡증에서 초치료로 코 수술은 적합하지는 않지만 기도저항을 낮춰 continuous positive air pressure를 사용해야 할 때 이점이 있다고 하였다.

본 연구에서 과거 코골이 및 폐쇄성 수면무호흡증으로 본 원 또는 타 병원에서 수술을 받았지만 주관적 증상의 개선이 적다고 호소한 45 명의 환자들을 관찰한 결과 29 명에게서 비 중격 만곡증 또는 하비갑개 비대증이 있다는 것을 발견할 수 있었고 저자들은 그 원인을 초치료 전 의료진에 의한 불완전 한 비내시경술 등에 의한 신체검진, 환자에 의한 부정확한 비강호흡부전의 호소라고 생각한다. 비중격 교정술 및 하비 갑개 절제술 등 코 수술 이후에 수술 전, 수술 후 3개월 $\mathrm{AHI}$ 값 및 산소포화도 비교를 통해서 현저히 개선되었음을 알게 되었다. 또한 음향 통기도 검사는 $\mathrm{MCA}$ 와 V7 모두 수술 전과 수술 후 1 개월, 3 개월, 6 개월, 12 개월 비교를 통해 통계학적 으로 유의하게 증가됨을 보여 좁아져 있던 비강의 부피가 개 선됨을 알 수 있었고 이는 코 수술 이후 비내 공간의 증가로 인해 비저항이 감소하게 되었고 이로 인해 환자들이 수면 시 비강호흡이 원활해져 구강호흡의 의존을 줄임을 알 수 있었 다. 한편, VAS 점수를 통해 코골이의 정도 및 $\mathrm{ESS}$ 를 통한 주
관적 삶의 만족도를 분석한 결과 역시 코 수술 이후에 개선 되었음을 알 수 있었다.

Olsen과 $\mathrm{Kern}^{14)}$ 의 보고에 따르면 코골이 및 폐쇄성 수면 무호흡증 수술 전 비폐색의 상태나 정도가 수술 후의 결과 에 직접적인 영향을 미치지는 않는다고 하였으나, Elsherif와 Hussein $^{12)}$ 은 코골이 및 폐쇄성 수면무호흡증 수술 전 비폐 색과 코골이의 정도, 수술 후 비중격 교정정도 등이 비중격 교정술 후 코골이 및 수면무호흡증 증상 호전에 영향을 미치 므로 코골이와 비폐색이 동반되어 있을 때 먼저 비중격교정 술, 비성형술, 비용종 제거술 등의 코 수술을 시행해야 한다 고 하였다. 이에 저자들은 이러한 결과의 차이가 나타나는 이유가 비폐색의 심한 정도의 차이가 개인마다 다르며 예측 하기 힘들고 결과에 대해 주관적으로 환자가 반응하기 때문 이라고 생각한다. 비록 코골이나 폐쇄성 수면무호흡증 수술 받은 환자 중에서 증상이 여전히 있는 환자 모두가 코 수술을 받을 경우에 해당하지는 않겠지만, 비중격 만곡증 또는 하비 갑개 비대증이 있는 환자의 경우에 코 수술을 시행하여 비폐 색을 해결하게 된다면 수면 중 기도폐색을 줄이는 데 효과적 이라고 생각된다. 또한 수면무호흡증 수술 전에 자세하고 정 확한 신체 검진을 통해 비폐색을 확인하고 구개수구개인두 성형술 등 폐쇄성 수면무호흡증 수술 시에 코 수술까지 시행 하여 비폐색도 해결해야 할 것으로 생각된다.

하지만, 환자의 수가 적다는 점과 수면다원화검사의 항목 개수가 적다는 점이 본 연구에서 아쉬운 점이고, 특히 추적 관찰 기간이 비교적 짧아 12 개월이라는 비교적 단기간의 효 과만 반영이 됐다는 점이 이 연구의 한계라고 할 수 있어 앞 으로 장기간의 기간 또는 많은 환자의 수에 대한 연구가 필 요할 것으로 사료된다.

\section{REFERENCES}

1) Chung YS, Hwang SH, Kim ST, Park JS, Cha HE, Kim DY. The effects of septal surgery for snoring and obstuctive sleep apnea (OSA) on polysonography (PGS). Korean J Otolaryngol 2002;45 (11):1081-5.

2) Fairbanks DN. Effect of nasal surgery on snoring. South Med J 1985; 78(3):268-70.

3) Zwillich CW, Zimmerman J, Weil JV. Effects of nasal obstruction on sleep in normal men. Clin Res 1979;27:405.

4) Jang HU, Jung SS, Nam YM, Kim JS. The effect of septoturbinoplasty for quality of life in patients with sleep-disordered breathing. Korean J Otorhinolaryngol-Head Neck Surg 2011;54(4):257-64.

5) Choi JH, Lee SH, Lee HM, Lee JK, Kwon SY, Shin C, et al. Correlation between quality of life and personality, behavior problem in children with sleep disordered breathing. Korean J Otolaryngol-Head Neck Surg 2005;48(10):1235-41.

6) Choi JH, Kim EJ, Kim YS, Kim TH, Choi J, Kwon SY, et al. Effectiveness of nasal surgery alone on sleep quality, architecture, position, and sleep-disordered breathing in obstructive sleep apnea syndrome with nasal obstruction. Am J Rhinol Allergy 2011;25(5): 338-41. 
7) Kim ST, Choi JH, Jeon HG, Cha HE, Kim DY, Chung YS. Polysomnographic effects of nasal surgery for snoring and obstructive sleep apnea. Acta Otolaryngol 2004;124(3):297-300.

8) Hong SK, Park MH, Lee IK. Long-term outcome of uvulopaltopharyngoplasty in obstructive sleep apnea syndrome patients: comparison between changes of subjective symptoms and objective indexes including respiratory and sleep parameters. Korean J Otolaryngol 1997;40(9):1313-8.

9) Masdon JL, Magnuson JS, Youngblood G. The effects of upper airway surgery for obstructive sleep apnea on nasal continuous positive airway pressure settings. Laryngoscope 2004;114(2):205-7.

10) Ellis PD, Harries ML, Ffowcs Williams JE, Shneerson JM. The relief of snoring by nasal surgery. Clin Otolaryngol Allied Sci 1992;17(6):
525-7.

11) Olsen KD, Kern EB, Westbrook PR. Sleep and breathing disturbance secondary to nasal obstruction. Otolaryngol Head Neck Surg 1981; 89(5):804-10.

12) Elsherif I, Hussein SN. The effect of nasal surgery on snoring. Am J Rhinol 1998;12(2):77-9.

13) Sufioğlu M, Ozmen OA, Kasapoglu F, Demir UL, Ursavas A, Erişen $\mathrm{L}$, et al. The efficacy of nasal surgery in obstructive sleep apnea syndrome: a prospective clinical study. Eur Arch Otorhinolaryngol 2012;269(2):487-94.

14) Olsen KD, Kern EB. Nasal influences on snoring and obstructive sleep apnea. Mayo Clin Proc 1990;65(8):1095-105. 